\title{
A BEAUTIFUL LIFE AS AN END OF EDUCATION
}

\author{
CHRISTOPH TESCHERS \\ christoph.teschers@ canterbury.ac.nz \\ University of Canterbury
}

\begin{abstract}
Following the theme of a conference held in Christchurch, New Zealand in 2016, this article explores the notion of "enabling students to live a beautiful life" as a possible end of education. A distinction is made between short-term, contextual aims in education and overarching, encompassing end(s) of education. Following Dewey, educational aims are considered to be manifold and to change over time within a sociocultural context, whereas a proper end of education, if such a thing exists, could be seen as "the best possible realization of humanity as humanity." Drawing further on the work of R. S. Peters, who contests the existence of any final end of education other than education itself, it can be seen that proposing such an end can be a challenging undertaking. Nevertheless, this article argues for a possible humanistic end of education, building on Schmid's philosophical concept of the art of living in conjunction with the German notion of Bildung and Aristotle's concept of phronesis, consolidating Peter's and Dewey's positions. An argument is made that a, if not the end of education would be to support every person as much as reasonably possible to develop their own art of living and live a good and beautiful life. Resulting implications for schooling, curricula and education systems are explored to show how education understood in such way transcends theory into practice.
\end{abstract}

Keywords: aims and ends of education; good life; Dewey; R. S. Peters; Wilhelm Schmid

\section{Exploring Educational Aims}

Education, when discussed in both public and political forums today, is often approached with the question: what can education do for a country's society and economy? From a society and community perspective, this question is important and cannot be ignored; however, it will be argued here that approaching education from this perspective alone is not enough and falls short to do justice to education and its role for human beings as individuals and members of society. Therefore, following an argument presented by Eckard Liebau (1999), it is necessary to reverse this question and ask "what structure a society should have, to be capable and willing to provide for people's educational demands" (p. 5, my translation, italics added). This inversion, Liebau argues, raises a number of questions, 
including "the question of schooling: What does schooling contribute to education - and what can and should it contribute?" (p. 5, my translation).

What is raised here are a number of issues regarding aims in and ends of education, beginning with the understanding of the term "education" itself. Education can be understood as (i) knowledge, Bildung (i.e. self-formation, cultivation and practical wisdom) and understanding that can be acquired, as (ii) the education process of teaching and learning, and it can refer to (iii) the education system as a whole, which will be termed schooling for the purpose of this article. What education, the education process, and schooling can and cannot do, and should and should not do, is certainly connected, as are their aims and ends. These can, however, also be quite different from each other. It will be argued that aims that are voiced in relation to either education, the education process, or schooling are further dependent on the perspective of the person or entity who is formulating these aims: these include, among others, the student, the teacher, the school, the parents, the local community, society as a whole, government officials and policy makers, and industry and economy representatives. Although all these "stakeholders," as people and bodies with an interest in education are often called in current neoliberal terminology (but which shall be avoided in the further discussion), have their own agendas and aims for a country's education system, including the educational content that is deemed important, I will focus on the main agents with a traditional interest in educational processes and outcomes: students, teachers, and society - understood here as a community of individuals sharing resources and common interests. To start this contemplation, a short narrative will be presented to illustrate some traditional perspectives regarding education:

Set in a traditional culture of early settlement, imagine a number of young people sneaking away from the village one day to explore the neighbouring woods, when they stumble upon a small clearing where one of the tribe's men is working on carving a bow. The boys know that he is the most skilled member of their village and every hunter wants to have a bow made by this bow-maker. Initially captivated by the deliberate and careful process of shaping and making a bow, the boys stand and watch for a while. However, most lose interest after a while and take off to explore the woods further. One boy, however, is so fascinated by the process that he sits down and watches the bow-maker. Occasionally, he might ask a question to understand what the man is doing and why. The boy finds himself to be so interested in the process of carving and making of bows, that he comes back the next day and the day after. On the third day, the boy brings with him a fresh hazelnut stick, as he learned that hazelnut wood is flexible and well suited for bow-making. The bowmaker, who is aware of the importance of his trade for the community and is genuinely interested in passing on his expertise to an interested youth, helps the boy with all the little steps that are needed to make his first bow. 
A number of important aspects for education and the process of education can be found in this short vignette, which could be considered as the beginning of an educational apprenticeship relationship. For once, we can see the educational triangle of student, teacher and topic; further, we can see that the well-being and continuation of the community play a role in the considerations of the bow-maker for teaching the boy. This emphasises the role of education for the survival and growth of the community. We also find a notion of specialisation and taking different tasks within a community for the benefit of all, which allows the bowmaker to carve bows but still be nourished and provided for by the rest of the tribe. From the student's perspective, interest is a key theme in this narrative, as it supports the boy's curiosity and he continues his observation when his friends move on. It also keeps him motivated over time to learn more and to try for himself. I would argue that, although societies are more complicated than portrayed in the rather simplistic setting of this short narrative, it still illustrates some of the key aspects that need to be considered in the context of aims in and ends of education: the interest and motivation of the teacher, of the student, and the matter at hand.

In this article, the notions of ends and aims of education will be critically discussed and an argument be made that, although many aims exist, a potential end of education can be formulated, drawing on Schmid's (2000) concept of the art of living. Some implications for schooling will be explored and a call be made to shift the focus of current education systems towards the development of a good and beautiful life for all children in their diversity and uniqueness.

\section{Distinguishing Educational Aims and Ends}

Although often used synonymously in the public arena, a distinction shall be made here between aims in education and ends of education. As John Dewey $(1916 / 2001)$ wrote, aims in education are manifold and have to be negotiated by each generation anew. Aims in education are, therefore, contextual and dependent on the historical, cultural, social and individual circumstances that are relevant for each educational setting. Aims are understood here as achievable, measurable, relatively narrow in focus, contextual, and potentially subjective, depending on each agent's perspective and role. Therefore, it can be argued that any contemplation of aims in education, as understood here, refers to the above mentioned interpretation of the process of education, as in teaching and learning, or deliberate educational settings such as schooling. Education in the meaning of having knowledge, Bildung, understanding, prudence and practical wisdom cannot have aims per se, only end(s), as aims include deliberate intention which again requires a person or entity representing one or multiple persons (Dewey, 1916/2001, p. 112). The aims of the bow-maker, for example, might be to pass on his knowledge and expertise for the good of the tribe, but also because he might be proud of his craft and wants to pass it on to the next generation. The aim of the 
tribe to allow the bow-maker to take the time for his work and to teach the young person is likely the benefit of good bows that support the survival of all. The student's aim, so we can assume, is, beyond intrinsic motivation, to learn a craft that he is interested in and that gives him purpose and a place in the community. The matter at hand, the knowledge and skill to make bows does not have an aim of its own, but the end of supporting the hunters in their ability to provide game for the community.

Returning to Dewey's discussion of educational aims, he identifies three main areas that seem to encapsulate most aims people associate with education: (i) the natural, individual development as portrayed by Rousseau; (ii) socialisation (or social efficiency); and (iii) personal mental enrichment or culture (p. 129). As mentioned above, aims are also dependent on one's viewpoint. A student engaging in educational processes might see education as a means to learn about something she is interested in, she might want to be able to get a job and make money, she might feel the desire to contribute to society in a meaningful way, or she just might want to get good grades to please - or not upset - her parents. A teacher might take pleasure in teaching young people, he might be passionate about his subject and others sharing his passion, he might want to see his students flourish, he might see teaching as an important contribution to the continuation and development of society, or all of the above; he might just want to get good performance reviews to have a secure job and make a living. Students' and teachers' aims in education are, one could argue, personal and individual, often multiple aims existing in parallel, and, although often being similar within each group, they can potentially be quite different between these two participating groups of educational processes. Aims of a more structural level are raised by society, mostly expressed through educational policies, rules and curricula on a school, state or national level. It is probably not unreasonable to say that aims proposed on behalf of a society are mostly intended to cater for the perceived well-being and good of this society as a whole. If this includes the well-being of each individual, the greatest good of the most, or the greatest good of the ruling class depends on the social, cultural and political structure present in each system; an aspect that will be revisited later on.

Following this brief reflection on aims in education, the question arises if there is or can be a single end of education, and if it would be the same for education, the education process, and schooling. Ends of education are understood here as inherent to education (knowledge, Bildung, understanding) and, by extension, the education process that leads to 'having an education,' being educated, and acquiring Bildung. Ends are seen here, in contrast to aims, as broad in scope, holistic, unspecific, and non-prescriptive. Two notable educational theorists who contributed significantly to the discussion around possible ends of education are Dewey (1916/2001), as mentioned above, and R. S. Peters (1973). Peters argues that there should not be a proclaimed final end of education, as any such end would bear the potential to be a dangerous undertaking, as terrible things have been done by passionate (and fanatic) advocates of final ends of education (pp. 130-131). 
Peters argues against reducing education to be a means to an end and rather advocates for education to be an end in itself: "there is a quality of life embedded in the activities which constitute education, and ... 'life' must be for the sake of education, not education for life" (p. 131). Peters' warning is an important one, as indeed any prescribed end of education external to education itself, even wellintentioned ends such as "self-realization, the greatest happiness of the greatest number" (p. 130), or the idea of a social democratic citizen demotes education as a means and opens the door for "an instrumental way of looking" at education, which allows for a potentially restrictive and exclusive approach to schooling. The question that arises here is, if these mentioned "ends of education," which Peters also refers to as aims in places, are actually ends of education or rather structural aims proposed by society. One could argue that aims, as they are intentional and therefore formulated by persons, are by definition extrinsic to education; however, an end of education that emerges from the role that education plays for human beings, would be intrinsic and not reduce education as a means to an end but rather describe the intrinsic role and importance of education itself.

Reflecting on Aristotle's notion of eudaimonia in his Nicomachean Ethics, and his claim that human beings strive in all they do to achieve eudaimonia, which effectively makes all human activity a means to this end of serene happiness, but that this serene happiness serves no other end than itself, would indicate that education itself would contribute to eudaimonia as an end for human beings. Similarly, Peters (1973) indicates that education might have another intrinsic purpose than education for its own sake, when he argues that "there is a quality of life embedded in the activities which constitute education" (p. 131). He acknowledges that engaging in education (not necessarily schooling) contributes to "a quality of life," which could be understood as a contribution to eudaimonia. Dewey (1916/2001), on the other hand, although similarly wary of the notion of a final end of education, does suggest "the promotion of the best possible realization of humanity as humanity" as a potential "proper end of education" (p. 100). What distinguishes both of these potential ends of education from the earlier formulations of aims on a personal and structural level are (i) a broadness that does not promote one way of living or thinking above another, and (ii) that both seem to emerge from education rather than being prescribed externally as something that education should cater for. However, where these two ends differ from each other is the point of reference: Peters' notion of a "quality of life" refers to an individual engaged in education and adding this quality to his or her life; Dewey's formulation of a proper end aims towards a structural end of the perfection, "the best possible realization of humanity." In the next section, I will explore if and how these two different positions could be consolidated towards a single end of education, which then should, as is argued in the final section, guide the aims we formulate for schooling and education systems today. 


\section{Consolidating Dewey's and Peters' Notions of Ends in Education through the German Notion of Bildung}

In this section, an attempt will be made to consolidate the two different positions for potential ends of education as discussed above. To do this, a short excursus will be taken here to explore the German notion of Bildung as a key aspect of education as it is understood in the German tradition.

Bildung, which is often translated as self-formation or self-cultivation, includes the aspects of knowledge, understanding, prudence and practical wisdom. It is understood as a formation of one's self through knowledge and understanding of the world, as much as this is possible, to develop prudence and practical wisdom. However, to be able to gain a certain understanding of the world we are living in and the workings of it, the knowledge necessary to achieve Bildung, needs to be broad and holistic. This understanding of education as Bildung impacts therefore on schooling and curriculum content. A person who has Bildung is considered a person of broad general knowledge, displaying prudence and practical wisdom, but also being well versed in aspects of human culture and aesthetics (Liebau, 1999). To gain some understanding of human beings and their experienced life-reality in the world, one needs to have some insights into human culture and its expression in art, music, literature and philosophy. Therefore, a curriculum that focuses mainly on reading, writing, maths and the STEM subjects falls short of providing Bildung. It might provide the necessary skills for contributing to a society's industry and economy, although this can be questioned in a time where technical hands-on jobs are in decline and jobs in development, service and management are on the rise. The latter often require certain knowledge and understanding of human beings, social interactions, as well as critical, caring and creative thinking, learning often associated with humanities and social sciences. It is a holistic understanding of education that is represented in the German notion of Bildung, which is essential for the German understanding of pedagogy and schooling (Liebau, 1999).

According to Liebau, the notion of Bildung has its origin in the period of German Idealism and has strongly been influenced by Wilhelm von Humbuld at the end of the $18^{\text {th }}$, beginning of the $19^{\text {th }}$ century, who connected scientific and humanistic approaches to understanding the world with the notion of aesthetics. Hence, the strong links between Bildung and art, music and drama, and the common translation of Bildung as "self-cultivation." It also includes the assumption of Bildung being a life-long process of each individual to pursue one's own perfection as a human being. To relate back to the two proposed aspects of ends of education suggested by Peters and Dewey, the tradition of the German Bildung's Idealism can bridge this gap, I would argue, as German idealists proclaimed that the perfection of humanity, or the "best possible realization of humanity as humanity," to use Dewey's words, can only be achieved through the perfection of each individual human being through Bildung. Therefore, allowing and supporting all individuals to pursue Bildung, to develop their potential as human beings, and to partake in the "quality of life embedded in the activities 
which constitute education" (Peters, 1973, p. 131) on an individual level, supports, I would argue, Dewey's proposed "proper end of education" of the "best possible realization of humanity as humanity."

\section{A Beautiful Life as an End of Education}

Having argued how Dewey's and Peters' notions of potential ends of education can be consolidated through an understanding of education built on the German notion of Bildung, an end of education will be formulated in this section that, I would argue, includes the personal and social perspectives as discussed above, as well as keeps in mind the concerns raised by Peters. To do this, Schmid's (2000) philosophical concept of the art of living will be introduced here, which builds strongly on the notion of Bildung and provides an understanding of what is important to be able to develop one's own art of living and to live a good and beautiful life. This will be argued for as one end, and maybe even the end of education. It needs to be noted here that the line of argument presented here will be succinct as this point has been made before (Teschers, 2013); however, it is necessary to reiterate the key points for the following argument in this article.

Wilhelm Schmid (2000) is a contemporary German philosopher who has undertaken significant work towards a philosophical approach to the art of living. He advocates not for a fixed prescription of what a good and beautiful life looks like, but discusses the aspects relevant for the development of each individual's own art of living. To engage in and develop one's own art of living means, for Schmid, to take up responsibility for one's own life and to try to make it a beautiful life (Schmid, 2000; Teschers, 2010). The notion of a "beautiful life" is chosen deliberately by Schmid, as a "good life" has a number of existing and potentially conflicting and misleading normative interpretations, such as being financially well off, living a life of pleasures, or living a morally good life. A beautiful life, however, is a question of individual taste and cannot be prescribed; just as a painting or another work of art is judged as beautiful or ugly based on each individual's personal taste. Similarly, Schmid has chosen the notion of a "beautiful life" to emphasise that the art of living acknowledges that each individual has his or her own view on what it means to live a beautiful life. In this way, Schmid's concept of the art of living takes an individualistic approach in which each person actively shapes his or her own life according to what he or she considers to be beautiful.

It is important to emphasise this individualistic approach towards judging a life to be beautiful, as any prescription of how one ought to live to have a beautiful life will be exclusive and falls short to include the diversity of the perceptions human beings might have on living a beautiful life. This point is also key in response to Peters' cautioning notion of prescribed ends of education, and similar criticism would apply for any prescriptive notion of a good and beautiful life. For Schmid, each individual engaging in the art of living becomes an artist who is shaping his or 
her own life as a work of art. This, however, does not mean that all reins are off and one can do whatever one likes. Schmid acknowledges that human beings generally live in communities and societies and are subject to ethical and moral implications. Therefore, he developed, based on the Aristotelian notion of phronésis (prudence and practical wisdom), an ethics of the art of living that is based on the self-interest of each individual, which through practical wisdom is transformed into a form of enlightened self-interest in which the individual pursuing the art of living will recognise that it is in his or her own best interest to create an environment that is conducive to living one's own beautiful life. This environment, Schmid argues, includes that each person is supportive of other people's own version of living a beautiful life. Therefore, each individual engaged in the art of living should be considerate and supportive of the development of other people's art of living, which includes to respect personal boundaries and to abide by reasonable rules set by society (Schmid, 2000; Teschers, 2017).

Schmid's definition of the art of living is also an active one. "To take up responsibility for one's own life" means to be active, to take charge of one's own life and the direction one takes in life, instead of being driven by external circumstances (parents, peers, culture, society, etc.). For Schmid, the notion of (self-)reflection is important in this concept, as he argues that only a deliberate reflection and contemplation of the norms, values and beliefs one holds and is presented with by others (e.g. family, peers, culture, religion, society) allows the individual to consciously subscribe to certain norms, values and beliefs, instead of unconsciously adopting these in an unreflected manner. Through this active element of reflection and deliberate acceptance or rejection of norms and values one takes charge of those defining aspects of one's life that lead us to choose certain actions above others and to shape our self and our lives accordingly.

The final aspect reflected in the short definition provided above is the aspect of "trying." For Schmid, engaging in the art of living does not automatically mean to succeed in having a beautiful life, but trying to shape one's life towards what one would consider a beautiful life to be. This includes the idea of incompleteness; an unending strive towards a beautiful life which only ends with one's final breath. Indeed, for Schmid (2000a) the final argument or reason why human beings would engage in the art of living and would try to live good and beautiful lives would be the finality of life itself, which urges us to progress rather than to stay idle.

It has been argued elsewhere (Teschers, 2013) that education plays a relevant role for the development of a student's own art of living: through teaching and the development of relevant skills, such as critical, creative and caring thinking, (self-) reflection, as well as Bildung, the acquisition of relevant knowledge and the ability to "life-long learning." Schmid outlines a number of curriculum areas that are relevant for a person's life-cycle and therefore important for the development of an art of living and a beautiful life: the human being as individual; the social human being; difficulties and burdens of human life; striving for fulfilment and meaning in life; religions, beliefs and cultures of humanity; and the personal shape of one's 
life and global perspectives. Although it can be contested that these areas encompass all relevant aspects of a person's life-cycle, it seems intuitive that all these areas are relevant for people's lives today.

Schmid's concept of the art of living and education are therefore connected through education being able to support the development of students' own art of living. However, I have argued elsewhere (Teschers, 2013) that both also have a similar, if not the same end: to support human beings to live the best possible (most beautiful) life under the circumstances they are living in. Hence, the strive for a good and beautiful life connects with Aristotle's notion of eudaimonia in so far as both are an end in themselves, and education, I would argue, is both, a means to the end of living a beautiful life, but also, for many, a necessary component of a beautiful life and therefore an end in itself, as argued for by Peters.

Combing now Peters' notion of education as personal enrichment and Dewey's notion of the best possible realisation of humanity as humanity with the notion of Bildung and Schmid's notion of the art of living, it can be argued that a proper end of education (including the process of education) would be to support all human beings to life the most beautiful life possible under the circumstances they are living in (see also Teschers, 2013).

\section{Consequences for Schooling}

Having formulated a possible end of education and as education and schooling needs to be considered distinctly, as argued above, it is necessary to explore which consequences this end of education might have on a country's education system and curriculum.

To start with, I would argue that it is fair to say that a country's schooling system is led by the norms and values of this country's society, ideally represented through the country's government and leadership. For the sake of the argument at hand, I will assume that a country's leadership aims to fairly represent the norms and values of the people they serve, leaving out oppressive and non-representative systems. As societies are made of people, it would further be fair to assume that the norms and values shared as a society represent the key norms and values of (the majority) of the members of this society. If we follow Aristotle's argument that each human being strives for eudaimonia (serene happiness), one could assume that the norms and values held by each individual, if they are consciously reflected and not just adopted, are believed to support a life that is supposed to leads towards eudaimonia. The difficulty we face here is people's differing ideas of what leads towards a happy and content life. To complicate matters, psychologists have shown that people are generally not very good at predicting what actions and directions in life will lead to a happier and more content life (Schwartz, 2004; Seligman, 2010). From a philosophical perspective, we are also faced with the issue what "happiness" actually means and if what psychologists measure represents a notion of happiness that is similar to Aristotle's idea of eudaimonia. 
A response to these challenges can be found in Schmid's concept of the art of living. As has been discussed above, Schmid's art of living concept acknowledges an individual's question of taste in regard to living a beautiful life. It does not prescribe norms, values and how one ought to live, but allows for each individual to reflect on their own norms, values and to take a direction in life that they consider to lead towards a beautiful, perhaps eudemonic life. What follows for a country's education system is that, to represent all members of society, it should support not only a narrow prescribed way of living that a majority might agree on as potentially being a good life, but to support diversity in life-concepts beyond what would be considered 'the norm' within a society. The challenge for a society and their representatives, however, is to create a system that is holistically inclusive and feasible, while balancing people's personal desire to strive for eudaimonia and to endure a continuation of provisioning a society with necessary resources through industry and economy. One could argue that many countries, especially those in which a neo-liberal ideology takes precedence (e.g. Roberts, 2004), have focused more on the latter and the idea of supporting people's happiness has been swallowed by the ideology that for people to have a good life what we need in a country is economic growth. However, it has been shown that on a personal level more money, items and amenities beyond a certain, relatively modest point, does not increase a person's subjective well-being and enduring happiness in life (Csikszentmihalyi, 2008; Seligman, 2010). The mantra of more wealth equals happy people can therefore not be maintained. This then relates back to Liebau's inversion of the question of what education can do for society towards the question of what society can do for the educational needs of its members to enable them to live good and beautiful lives.

What follows from these contemplations is that the inherent end of education to support all human beings to live the most beautiful life possible can be transferred into an overarching aim for schooling and a country's education system, assuming that it is a commonly held value of a society to support its members to develop their own art of living and try to live a beautiful life based on their individually reflected norms and values and the implications of an ethics of the art of living as discussed by Schmid. Hence, what is argued for here is a re-focus on the humanistic aspects of education in addition to subjects and content areas that are important to find employment and become an active member of society. Not to forget the knowledge and understanding necessary for active democratic citizens in democratic societies (Dewey, 1916/2001).

To provide some concrete examples of implications for schooling, it is suggested here that school curricula are reviewed to incorporate more readily content areas that are relevant for the development of students' own art of living, such as the areas presented by Schmid above: the human being as individual; the social human being; difficulties and burdens of human life; striving for fulfilment and meaning in life; religions, beliefs and cultures of humanity; and the personal shape of one's life and global perspectives. In addition, some of the skills and 
faculties important for developing an art of living are critical self-reflection; critical, creative, and caring thinking; the development of practical wisdom; and an understanding of hermeneutical processes (Teschers, 2013, 2017). To incorporate all of these in meaningful ways in school curricula and teaching and learning would, it is argued here, support students more strongly to develop their own art of living, reflect on their own norms, values and beliefs, and to make prudent and reflected decisions.

\section{Conclusion}

This article has explored some of the common meanings of the term 'education' in the public and academic arena, it has highlighted that it is important to distinguish between these meanings for the discussion of aims and ends in education and an argument has been made that an intrinsic end of education would be to support the development of people's own art of living and ability to live their own beautiful lives. It has been further argued that, under assumption of Aristotle's claim that human beings generally strive for eudaimonia (serene happiness), it is a government's responsibility, as representatives of the people, to develop an education system and curriculum that supports this strive and allows for the diversity of the direction people might take (within reasonable constrains to ensure the peaceful continuation of society). This does not suggest abandonment of subjects and content areas that are important to be a successful member of a country's economy and industry, but to shift the focus again towards a more humanistic education that supports both: the necessity to work and move successfully within a society, and to gain the relevant knowledge and skills that are important for each person to develop their own art of living, to become the artists of their own lives, and to potentially shape these lives into beautiful works of art.

\section{REFERENCES}

Aristotle (n.d./1996). The Nicomachean Ethics. London, England: Wordsworth Editions Limited.

Csikszentmihalyi, M. (2008). Flow: The psychology of optimal experience. [Modern classics edn.]. New York, NY: Harper Perennial.

Dewey, J. (1916/2001). Democracy and education. Hazleton, PA: The Pennsylvania State University.

Liebau, E. (1999). Erfahrung und Verantwortung. Werteerziehung als Pädagogik der Teilhabe. [Experience and responsibility. Values-education as a pedagogy of participation.] Weinheim; München, Germany: JuventaVerlag.

Peters, R. S. (1973). Authority, responsibility and education. New York, NY: Paul S. Eriksson.

Roberts, P. (2004). Neo-liberalism, knowledge and inclusiveness. Policy Futures in Education, 2(2), 350-364. 
Schmid, W. (2000). Philosophie der Lebenskunst: Eine Grundlegung. [Philosophy of the art of living: a foundation.] Frankfurt, Germany: Suhrkamp.

Schwartz, B. (2004). The paradox of choice: Why more is less. New York, NY: ECCO.

Seligman, M. E. P. (2010). Authentic happiness: Using the new positive psychology to realise your potential for lasting fulfillment. London, England: Nicholas Brealey Publishing.

Teschers, C. (2010, 02-05 December 2010). "Lebenskunst" Schmid's Concept of the Art of Living. Annual Philosophy of Education Society of Australasia Conference. (Online proceedings). Perth, Australia: PESA. Retrieved from https://pesa.org.au/images/papers/ 2010-papers/pesa-2010-paper-02.pdf

Teschers, C. (2013). An educational approach to the art of living. Knowledge Cultures, 1(2), 131-144.

Teschers, C. (2017). Education and Schmid's Art of Living: Philosophical, psychological and educational perspectives on living a good life. London, England: Routledge.

Christoph Teschers is faculty member at the College of Education, Health and Human Development, University of Canterbury, New Zealand. He has published several articles and book chapters and is author of Education and Schmid's Art of Living (2018). Taking an interdisciplinary approach, he is mainly interested in the relationship between people's wellbeing, the philosophical notion of the art of living and educational theory and practice. Other areas of interest include philosophy for children, positive psychology, inclusive education, ethics and social justice. 